\title{
Health \& Wellness Centers to Strengthen Primary Health Care in India: Concept, Progress and Ways Forward
}

\author{
Chandrakant Lahariya ${ }^{1}$
}

Received: 23 March 2020 / Accepted: 18 May 2020 / Published online: 8 July 2020

(C) Dr. K C Chaudhuri Foundation 2020

\begin{abstract}
In February 2018, the Indian Government announced Ayushman Bharat Program (ABP) with two components of (a) Health and Wellness Centres (HWCs), to deliver comprehensive primary health care (PHC) services to the entire population and (b) Pradhan Mantri Jan Arogya Yojana (PMJAY) for improving access to hospitalization services at secondary and tertiary level health facilities for bottom $40 \%$ of total population. The HWC component of ABP aims to upgrade and make 150,000 existing Government Primary health care facilities functional by December 2022. The first HWC was launched on 14 April 2018 and by 31 March 2020, a total 38,595 AB-HWCs were operational across India. This article documents and analyses the key design aspects of HWCs, against core components of PHC \& the health system functions. The article reviews the progress and analyses the potential of HWCs to strengthen PHC services and therefore, advance Universal Health Coverage in India. Challenges emerged from COVID-19 pandemic \& learnings thus far has also been analyzed to guide the scale up of HWCs in India. It has been argued that effectiveness and success of HWCs will be dependent upon a rapid transition from policy to accelerated implementation stage; focus on both supply and demand side interventions, dedicated and increased funding by both union and state governments; appropriate use of information and communication technology; engagement of community and civil society and other stakeholders, focus on effective and functional referral linkages; attention on public health services \& population health interventions; sustained political will \& monitoring and evaluation for the mid-term corrections, amongst other. Experience from India may have lessons and learnings for other low and middle-income countries to strengthen primary healthcare in journey towards universal health coverage.
\end{abstract}

Keywords Ayushman Bharat program · Coronavirus · COVID-19 · Health \& wellness centres · India · Primary health care · Universal health coverage

\section{Introduction}

The primary health care system in India has evolved since independence and there is an elaborate network of nearly 200,000 Government Primary Health Care Facilities (GPHCFs), both in rural and urban areas (Box 1) [1-30]. The existing GPHCFs deliver a narrow range of services, due to variety of reasons including, at times, the non-availability of providers as well. Thus, the GPHCFs in India are grossly underutilized \& excluding for the mother and child health services, in $2013-14$, only $11.5 \%$ of rural and $3.9 \%$ in urban

Chandrakant Lahariya

c.lahariya@gmail.com

1 World Health Organization Country Office for India, New Delhi, India people in need of health services used this vast network [1, 2]. People in India either choose higher level of government facilities for primary health care (PHC) needs (which results in an issue of subsidiarity) or attend a private provider (which results in the out of pocket expenditure or OOPE), both situations are not good for a well-functioning health system. The challenge of weak PHC in India are increasingly being recognized and acknowledged. The National Health Policy (NHP) 2017 of India proposed to strengthen PHC systems, invest twothird or more government health spending on PHC, with an increase in overall government funding for health to $2.5 \%$ of Gross Domestic Product (GDP) by 2025, against $1.18 \%$ in 2015-16 [3]. Following on the NHP 2017, the Government in India announced Ayushman Bharat Program (ABP) in February 2018 with two components of (a) Health and Wellness Centres (HWCs) to strengthen \& deliver comprehensive Primary Health Care (cPHC) services for entire population 
Box 1 Evolution of Government PHC system in India [1-30]

Primary Health Care (PHC) has always been considered a foundation of stronger and efficient health systems. The efforts to strengthen health services, based upon stronger PHC in India started when the 'Health Survey and Development Committee' was established in 1943 under the chairpersonship of Sir Joseph Bhore [5]. India started setting up primary health centres (PHCs) in 1952, when the first few PHCs were established in Najafgarh (Delhi), Singur (West Bengal) and Poonammalle (Tamilnadu) under Community Development Program [6]. This was part of establishing a three-tier healthcare system in the country, which has evolved since then $[2,7,8]$. India started efforts to build health system around the same time when National Health Services (NHS) in United Kingdom was set up and the constitution of World Health Organization (WHO) came into force, both in year $1948[9,10]$. The successive governments continued to expand the network of PHCs, which received a major boost through various committees, set up nearly one to three in every decade for first 4 decades [11]. The efforts to strengthen PHC system in rural India have been made over the years [1, 3, 4, 12-20]. With these initiatives, by mid Sept 2019, country had an extensive network of 158,417 Health Sub Centres: 25,743 Primary Health Centres in rural areas; 5,624 Urban PHCs; 764 district hospitals; 539 medical colleges and hospitals and 1,741 mobile medical units [7, 8]. The annual admission capacity in medical colleges was 80,000 for graduate medical seats and 41,000 for post graduate courses.

The efforts to strengthen PHC network in India apparently received a boost after Alma Ata conference on primary health care in 1978 and then with the release of India's first National Health Policy in 1983 [14, 21]. A major initiative to further strengthen \& make rural PHC system functional, started in April 2005, with the launch of National Rural Health Mission (NRHM) in India [22] soon after the second national health policy in 2002 [23]. The urban component as National Urban Health Mission was launched in May 2013 [24]. Two missions together were, thereafter, renamed as National Health Mission (NHM) [22-24]. The NRHM/NHM has focused on PHC system strengthening to make it functional to deliver services. NRHM/NHM had a few strategies to strengthen health systems and PHC services: decentralized health planning; communization (community processes, behavior change communication and addressing social determinants of health); social protection function of public health services; partnership for NGOs and civil society; human resource strengthening; flexible funding for states, public health management and many others [22, 25].

The NRHM/NHM in India is attributed to improving several services, though mostly Reproductive Maternal, Newborn, Child and Adolescent Health (RMNCH+A) services through Government Primary Health Care Facilities (GPHCF). The reduction in Infant Mortality Rate (IMR) and Maternal Mortality Ratio (MMR), which these programs specifically targeted, were reduced at accelerated manner and India reached very close to achieve Millennium Development Goals (MDG) 4 and 5 [26]. Yet, it was increasingly being recognized that health services for emerging burden of diseases and changing epidemiological profile, i.e., Non-communicable diseases (NCDs) through GPHCFs were either not available or insufficient. The need for a new approach to deliver comprehensive PHC was felt. It was also the time when various discourses on Universal Health Coverage (UHC) were happening in India [27-29]. The ongoing \& identified challenges of GPHCFs include a narrow range of services, insufficient infrastructure, shortage of healthcare providers; lack of medicines and diagnostics, and limited referral services. These challenges have been documented in various review missions and also captured in situation analysis document of NHP 2017 [1, 3, 30].

and (b) Pradhan Mantri Jan Arogya Yojana (PMJAY) for secondary and tertiary level hospitalization services for bottom $40 \%$ of families in India [4]. The details of ABP in the context of Universal Health Coverage (UHC) has been published earlier [1] and a schematic of ABP is provided as Fig. 1. These two arms, hence onwards, in this article, have also been referred as AB-HWCs and AB-PMJAY, to indicate that both are component of ABP.
This review article describes the concepts, provides an update on implementation of two components of ABP; documents $\&$ critically analyzes initiatives under AB-HWC in context of delivery of comprehensive $\mathrm{PHC}(\mathrm{cPHC})$ service \& proposes a few ways-forward. Early reflections on how challenges posed by and initial learnings from the response to Corona virus (SARS-CoV-2) disease or COVID-19 pandemic could be used for scale-up of HWCs in India, have also been summarized.
Fig. 1 Ayushman Bharat Program in India: a schematic

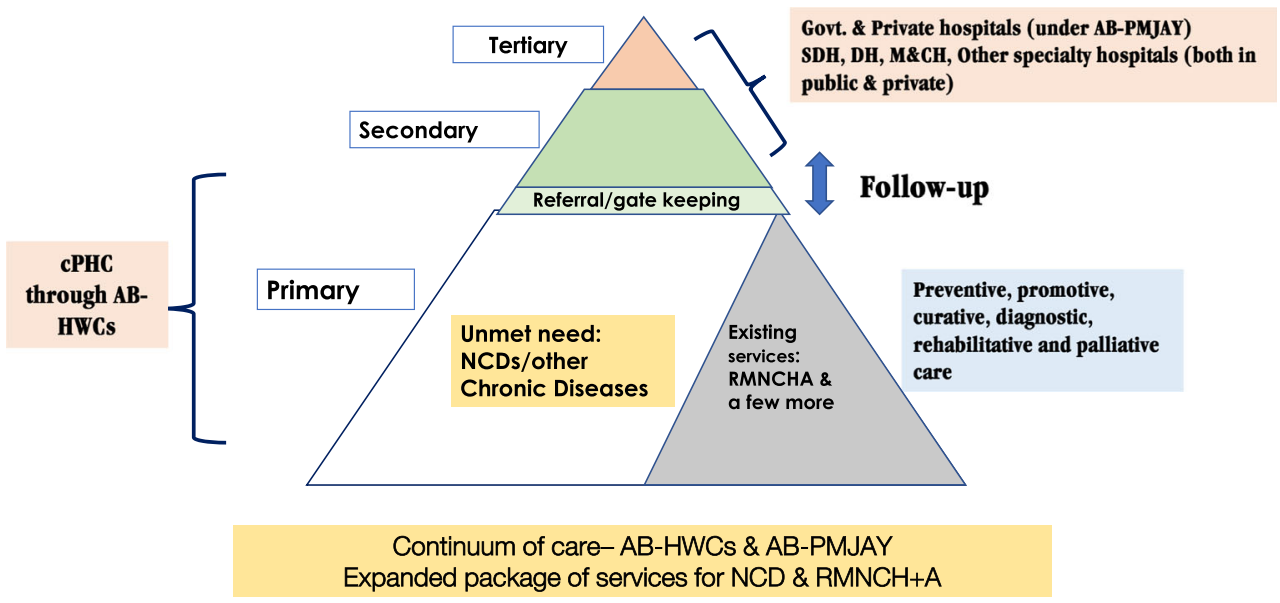

AB-HWCs Ayushman Bharat- Health \& Wellness Centres; AB-PMJAY Ayushman Bharat- Pradhan Mantri Jan Arogya Yojana; $c P H C$ Comprehensive Primary Health Care; DH District hospitals; $N C D$ Non-communicable diseases; $M \& C H$ Mother and Child Health; $R M N C H+A$ Reproductive Maternal, Newborn, Child and Adolescent Health; SDH Social determinants of health 
Table 1 Evolution of Health \& Wellness Centres (HWCs) in India [1, 3, 4, 30]

\begin{tabular}{|c|c|}
\hline Timeline & Specific developments \\
\hline July- Dec 2013 & Initial discussion on Health and Wellness Centres (HWCs) in India started \\
\hline 2015-16 & Task Force on Primary Healthcare in India recommended formation of HWCs, with initial suggestions on the design. \\
\hline 2017 & $\begin{array}{l}\text { India's third National Health Policy (NHP 2017) released. } \\
\text { Union Budget announcement for setting up HWCs in India }\end{array}$ \\
\hline 2018 & $\begin{array}{l}\text { HWC became one of the two pillars under Ayushman Bharat (AB) program announced in Union Budget } \\
\text { on } 1 \text { February } 2018\end{array}$ \\
\hline 14 April 2018 & Inauguration of India's first AB-HWC at Jangla, Bijapur, Chhattisgarh, India \\
\hline 31 March 2019 & $\begin{array}{l}\text { A total of 17,149 AB-HWCs made functional across India. This includes 8,801 Primary Health Centres; 6,795 } \\
\text { Health Sub-centres (HSC) and 1,553 Urban Primary Health Centres (UPHCs) converted to HWCs. }\end{array}$ \\
\hline 2019-20 & $\begin{array}{l}25,000 \text { additional AB-HWCs to be set up with all UPHC to be converted to HWCs in the financial year. A total } \\
\text { of } 38,595 \text { HWCs were set up by } 31 \text { March } 2020\end{array}$ \\
\hline 31 December 2022 & Indian states to have 150,000 functional AB-HWCs in the country \\
\hline
\end{tabular}

\section{Health \& Wellness Centres (HWCs) and Comprehensive Primary Health Care in India}

The first HWCs was launched in Jangla village in Bhairamgarh tehsil of Bijapur district of Chhattisgarh state in India on 14 April 2018 [1, 4]. The key events related to HWCs in India are summarized in Table 1. As part of HWC components of ABP, the govt of India announced to make existing 150,000 GPHCFs in country functional by December 2022. AB-HWCs are not new facilities and are being set up as an upgraded version of existing GPHCFs such as Health Sub-Centers (HSC); Primary Health Centers and Urban Primary Health Centers (UPHCs). The proposed increase in provision of services (shift from erstwhile provision of 6 sub-group of services to 12 sub-group of services) and upgrade on other key design aspects are shown in Figs. 2 and 3 [1, 31].

Against the target of 15,000 of HWC in year 1, a total of 17,149 AB-HWCs were made functional by 31

Fig. 2 Key components and design aspects of AB-HWCs [1, 31]
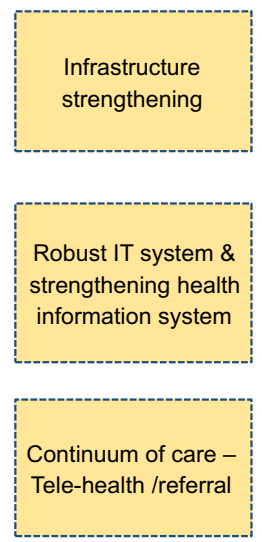

March 2019 [30]. Cumulative target of 40,000 HWCs was set up for 31 March 2020. There was slow-down in setting up HWCs in March 2020 due to COVID-19 pandemic and total of 38,595 HWCs were operational by 31 March 2020. The cumulative target is 70,000 HWCs by 31 March 2021, then 110,000 by 31 March 2022 and 150,000 by 31 December 2022. Alongside, all UPHC across India were to be converted to HWCs by March 2020 [1]. Official data on utilization of services from HWCs was available till 22 Sept 2019, when nearly 21,000 AB-HWCs were operational which had reported a foot-fall of 17 million. In these Centres 950,000 yoga sessions were conducted; 7 million people received treatment for hypertension and 3.1 million for diabetes mellitus, Sixteen million beneficiaries received essential medicines and 4.9 million received free essential diagnostics [1, 32]. The second component of AB-PMJAY was launched on 23 Sept 2018 and progress on this component is summarised in Box 2 [32, 33].

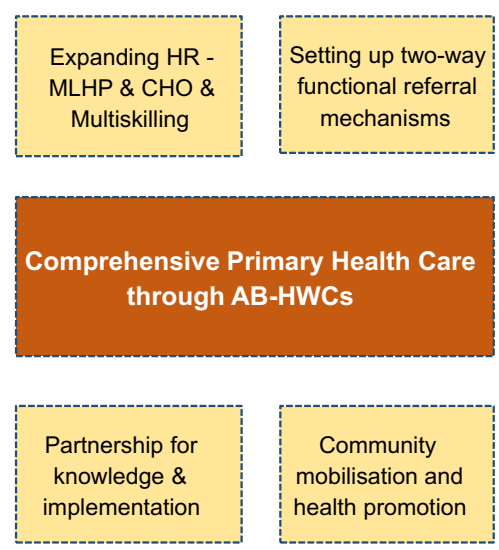

AB-HWCs Ayushman Bharat- Health \& Wellness Centres; $C H O$ Community health officers; HIS Health information system; HR Human resources; MLHP Mid-level healthcare provider; IT Information and technology 
Services through existing GPHCFs

General out-patient care for acute simple illnesses \& minor ailments

Family planning \& other reproductive health services

\section{Neonatal and infant health care services}

Care in pregnancy and child-birth.

Childhood and adolescent health care
services.

Services added as part of AB-HWVS

Screening and Management of NonCommunicable diseases

Screening and Basic management of Mental health ailments

Care for Common Ophthalmic \& ENT problems

Basic Dental health care

Geriatric and palliative health care

services

Basic Trauma Care and Emergency

Medical services.

AB-HWCs Ayushman Bharat- Health \& Wellness Centres; GPHCFs Government Primary Health Care Facilities

Fig. 3 Service provision through AB-HWCs $[1,31]$

The HWCs aims to address the identified challenges in PHC systems in India, by focusing upon holistic PHC strengthening through various initiatives [Table 2 (structured as per health system functions)]. This is not first such initiative to strengthen PHC services in India. Yet, why AB-HWCs appears more promising than all earlier initiatives to strengthen and deliver comprehensive PHC has been explained in Appendix 1 [1, 3, 27-29, 31-37]. This is relevant considering much of 14 y since the launch of National Rural Health Mission (NRHM) in the year 2005, had also focused on strengthening PHC system in the country.

\section{Making Health \& Wellness Centres of India Work}

HWCs aim to build upon what has been started under NRHM/ National Health Mission (NHM). However, considering even in the past, the similar attempt to strengthen PHC services have met partial success, more is needed to ensure that $\mathrm{AB}$ HWCs does better than the initiatives in the past. Therefore, it will be important that learnings from past are used and challenges identified, and focused attention is given to effective scale up. A few approaches could be as follows:

First, give sufficient attention, visibility and priority to $\mathrm{AB}$ HWCs as vehicle to strengthen primary health care services.

Box 2 Progress under Pradhan Mantri Jan Arogya Yojana (PMJAY) component of Ayushman Bharat in India [1, 32, 33]

Ayushman Bharat Program, from the time of announcement has two components. Other than Ayushman Bharat- Health and Wellness Centres (AB-HWC), AB-PMJAY is the second component. It has built upon the erstwhile Rashtriya Swasthya Bima Yojana (RSBY), started in year 2008 in India. Even since announcement of ABP, the scheme has witnessed a few evolutions in name before settling for AB-PMJAY. It was announced as AB-National Health Protection scheme or AB-NHPS in February 2018, renamed as National Health Protection Mission (AB-NHPM) in early March 2018 and then Pradhan Mantri Rashtriya Swasthya Suraksha Mission (PM-RSSM) in third week of March 2018. In mid August 2018, it was referred as Pradhan Mantri Jan Aarogya Abhiyan (PMJAA) (15 August 2018) before finally being renamed as AB-PMJAY towards the end of Aug 2018. AB-PMJAY provides health cover of up to INR 500,000 (Exchange rate in April 2020: 1 USD= approx. 75 INR) per family per year on floater basis; covers 3-day pre-hospitalization and $15 \mathrm{~d}$ post hospitalization; expenses on medicines, follow up and diagnostics. One thousand three hundred ninety three procedures in 24 specialties were part of the scheme, as on October 2019. There is no cap on family size, age or gender, cashless and paperless treatment for beneficiaries at point of care. Benefits are portable across the country in the empaneled hospitals.

The scheme was announced in Union Budget of India on 1 February 2018; Cabinet approval was received on 21 March 2018; National Health Agency got incorporated on 11 May 2018; AB-PMJAY was formally launched on 23 September 2018, from Ranchi, Jharkhand. On completion of $100 \mathrm{~d}$ of launch on 2 January 2019; National Health Authority or NHA was formed.

At $1 \mathrm{y}$ of completion of AB-PMJAY on 22 Sept 2019; a total of 32 states of 36 states/UT were implementing the scheme. One hundred and three million e-cards were issued. There were 18,236 hospitals empaneled [8,571 (47\%) public and 9,665 (53\%) private] and there were 4.65 million total hospital admissions with 2.18 million (47\%) in govt. and 2.47 million (53\%) in private facilities. The total treatment equal to Indian Rupee (INR) 7,490 Cr (US\$ 1.07 billion) was provided, which included INR 2,846 Cr (38\%) in Public and INR 4,644 Cr (62\%) in private sector facilities. 
Table 2 Challenges in PHC system, provisions through AB-HWCs and complementarity with NHM in India [1, 3, 27, 28, 31]

\begin{tabular}{|c|c|c|c|}
\hline $\begin{array}{l}\text { Health System } \\
\text { Function }\end{array}$ & $\begin{array}{l}\text { Challenges in PHC system } \\
\text { (Indicative) }\end{array}$ & $\mathrm{AB}-\mathrm{HWC}$ and related initiatives & $\begin{array}{l}\text { Ongoing and other proposed initiatives } \\
\text { (including NHM \& other state specific }\end{array}$ \\
\hline
\end{tabular}

\begin{tabular}{cc}
\hline $\begin{array}{c}\text { Service provision } \\
\text { and delivery }\end{array}$ & - \\
& (morrow range of six services \\
& child health and infectious \\
diseases) & - Curative care predominance \\
- 'Continuum of care' mostly for \\
maternal and child health services
\end{tabular}

- Stronger focus on service delivery with - Community based network of ASHA an enhanced package of 12 services and VHNSC to support preventive (from existing 6 services) and promotive health services.

- Attention on preventive and promotive - State specific models of service health services; focus on wellness and delivery to provide cross learnings lifestyle modification, specifically for - Build on systems for emergency chronic diseases

- Integration with Indian systems of medicine, AYUSH, including the promotion of Yoga as form of lifestyle change to tackle non-communicable diseases

- Population based screening for common conditions including three cancers

- Attention on quality and patient safety; Develop standard treatment flows (STF) for peripheral health facilities

- Extending prescription rights to $\mathrm{CHO}$ referral and transport; established under NHM

- Utilise strengthening of secondary care services \& District hospitals for effective referral linkage

- Build upon quality standards and mechanism for ensuring use of treatment protocols

- Community Health Officers (CHO) proposed in the National Medical Commission (NMC) Act to strengthen public health service delivery

Human resources - Shortage of infrastructure and and infrastructure human resources

- Inequitable distribution

- Health Sub-centres (HSCs) led by one or two Auxiliary nurse midwife (ANM) who has focus on Mother and child services

- Narrow range of skills and services at lower level PHC facilities

Health financing through legal process

- Adopt 'Resolve more \& refer less' approach at peripheral health facilities; strengthening of referral system to ensure continuity of care; Telemedicine and consultations

- Enhanced provision of point of care diagnostics at both levels HWC- HSC and HWC-PHC

- Provision of Mid-level healthcare provider (MLHP), trained in 6-month course at AB-HWCs to address common health problem

- Institutional strengthening for increased annual production of MLHP

- Task shifting to different cadre of healthcare providers and team-based service delivery

- Proposal to change the roles of ANMs as multi-purpose workers (female) or MPW- F

- Services at the HWC-HSC, to be delivered through a team, led by a new cadre of non-physician health worker, a MLHP or CHO, supported by one or two multipurpose workers, and ASHAs

- Shift from doctor centric facilities to a team-based service delivery where provision of providers is dependent upon service need

- AYUSH providers to be mainstreamed in PHC systems

- Reforms on provider payment mechanisms including the introduction of performance-linked incentives in PHC system

- Mechanisms to reduce cost of health seeking through assured provision of more medicines and point of care diagnostics

- Limited government funding on
health

- High OOPE to the range of $60 \%$ of total health expenditure

- Budget mostly line item-based funding only

- Limited use of strategic purchasing services

- People get poor because of health expenditures
- Performance-linked payments to the MLHP and to the team of front-line workers.

- MLHP to get salary on blended formula -a fixed component and incentives linked to key outcomes, measured
- Recruitment of contractual providers in the system

- Flexibility to states in salary for HR, under NHM to ensure recruitment

- Institutionalize the mechanisms for training of MLHP

- Consider an All India cadre of specialist doctors to tackle shortage of specialist doctors \& that of public health specialists

- Innovation in human resources including incentives to recruit and retain

- Increased government allocation for primary health care, through formula-based approach and sharing between union and state level

- Capacity building of states in health financing 
Table 2 (continued)

\begin{tabular}{|c|c|c|c|}
\hline $\begin{array}{l}\text { Health System } \\
\text { Function }\end{array}$ & $\begin{array}{l}\text { Challenges in PHC system } \\
\text { (Indicative) }\end{array}$ & $\mathrm{AB}-\mathrm{HWC}$ and related initiatives & $\begin{array}{l}\text { Ongoing and other proposed initiatives } \\
\text { (including NHM \& other state specific) }\end{array}$ \\
\hline & & $\begin{array}{l}\text { through IT platform-based monitoring } \\
\text { system with key performance indica- } \\
\text { tors }\end{array}$ & \\
\hline $\begin{array}{l}\text { Medicines and } \\
\text { vaccines }\end{array}$ & $\begin{array}{l}\text { - Many states started free medicines } \\
\text { and diagnostics scheme, yet govt } \\
\text { spending as share on cost of } \\
\text { medicines low } \\
\text { - Medicines and access to } \\
\text { diagnostics mostly at higher level } \\
\text { facilities and no assured provision } \\
\text { - Medicines major cost paid by } \\
\text { people } \\
\text { - Irrational use of medicines }\end{array}$ & $\begin{array}{l}\text { - Revision and expansion of essential } \\
\text { medicines \& diagnostics lists } \\
\text { - Assured provision of larger basket of } \\
\text { medicines with inclusion of additional } \\
\text { medicines for chronic diseases } \\
\text { - Assured dispensing of medicines for } \\
\text { longer duration of } 4 \text { wk or more } \\
\text { - Attention on expanded range of } \\
\text { diagnostic services of Point of Care } \\
\text { - Proposal for rapid expansion of } \\
\text { Pradhan Mantri Jan Aushadhi stores } \\
\text { for low cost \& generic medicines } \\
\text { - Proposal for setting up state level } \\
\text { procurement and supply corporations } \\
\text { - Provision of dispensing medicines } \\
\text { from HWCs, for patients who need } \\
\text { long term treatment and initially } \\
\text { attended care at higher level of } \\
\text { facilities }\end{array}$ & $\begin{array}{l}\text { - Provision of free medicines and } \\
\text { diagnostics (as well as schemes) under } \\
\text { NHM } \\
\text { - Strengthening of Mission } \\
\text { Indradhanush for increasing coverage } \\
\text { with vaccines under Universal } \\
\text { Immunization Program } \\
\text { - Launch of state specific free medicines } \\
\text { and free diagnostics schemes with } \\
\text { enhanced budgetary allocation }\end{array}$ \\
\hline $\begin{array}{l}\text { Health information } \\
\text { systems }\end{array}$ & $\begin{array}{l}\text { - Weak health information system } \\
\text { - Limited use of ICT platforms } \\
\text { - Delay in recording and reporting } \\
\text { of health data }\end{array}$ & $\begin{array}{l}\text { - Attention to build a robust ICT system } \\
\text { for population enumeration, } \\
\text { enrolment, tracking and follow-up of } \\
\text { patients } \\
\text { - Attention on registration of } \\
\text { beneficiaries at associated HWC } \\
\text { facility } \\
\text { - Increased use of mobile based } \\
\text { technology and hand-held devices } \\
\text { - Provision of tele-health and } \\
\text { tele-medicine at each facility } \\
\text { - Use of Digital technology and ICT } \\
\text { platforms (proposed for) to ensure } \\
\text { continuity of care through universal } \\
\text { population empanelment and } \\
\text { registration to a HWC, facilitating } \\
\text { performance payments and ensuring } \\
\text { continuity of care and also for } \\
\text { improved recording \& reporting } \\
\text { system }\end{array}$ & $\begin{array}{l}\text { - Telemedicine and tele-radiology ser- } \\
\text { vices as per the local needs } \\
\text { - Health Management Information } \\
\text { System (HMIS) established }\end{array}$ \\
\hline $\begin{array}{l}\text { Governance and } \\
\text { leadership }\end{array}$ & $\begin{array}{l}\text { - Weak regulation } \\
\text { - Limited transition of policy into } \\
\text { implementation } \\
\text { - Health state subject and variable } \\
\text { priority } \\
\text { - The job -descriptions of various } \\
\text { health staff are not aligned with } \\
\text { the activities they do }\end{array}$ & $\begin{array}{l}\text { - High level political and administrative } \\
\text { priority assigned to AB-HWCs at all } \\
\text { levels } \\
\text { - System and coordination mechanism } \\
\text { being proposed to link PHC services } \\
\text { with AB-PMJAY } \\
\text { - National Knowledge Platform for } \\
\text { implementation \& operational } \\
\text { research } \\
\text { - Revisions of operational guidelines } \\
\text { - Enhanced community-based monitor- } \\
\text { ing for AB-HWCs. } \\
\text { - Regular reviews on progress and } \\
\text { performance } \\
\text { - Revision in responsibilities of auxiliary } \\
\text { nurse midwife to make them } \\
\text { multi-purpose workers }\end{array}$ & $\begin{array}{l}\text { - A number of governance and } \\
\text { leadership mechanisms were } \\
\text { established under NHM level } \\
\text { including mission steering groups at } \\
\text { top level to community based } \\
\text { VHSNC at village level. } \\
\text { - The Clinical Establishment } \\
\text { Registration and Regulation Act, } \\
2010 \\
\text { - Stronger community and civil society } \\
\text { participation in health services }\end{array}$ \\
\hline
\end{tabular}

AB-HWCs Ayushman Bharat- Health \& Wellness Centres; AB-PMJAY Ayushman Bharat- Pradhan Mantri Jan Arogya Yojana; ASHA Accredited Social Health Activist; HR Human resources; HWC-HSC Health \& Wellness Centres- Health Sub-Centers; HWC-PHC Health \& Wellness Centres- Primary Health Care; ICT Information and communication technology; NHM National Health Mission; NMC Act The National Medical Commission Act; OOPE Out of pocket expenditure; PHC Primary Health care; VHNSC Village health, nutrition and sanitation committee 
Of the two components in ABP, the HWCs seem to be getting comparatively less attention, in spite of being recognized that cPHC can take care of up to $80 \%$ of health needs [30, 38, 39]. AB-HWCs is also a more difficult component to implement than insurance-based AB-PMJAY. Getting less public and political attention may appear a minor issue but may result in lower prioritization. There is a need to bring attention back on AB-HWCs and make these politically visible through advocacy and evidence. There is role for technical experts, professional associations and civil society representatives in ensuring that $\mathrm{cPHC}$ is not lost in the noise for more secondary and tertiary care services. People also need to demand for better primary healthcare services from their elective representatives.

Second, develop a detailed 'primary health care investment plan' for India and Indian states. The policy announcements are often equated with political will. The real test of the 'political will' is whether policy announcements have been followed by commensurate, sufficient \& sustained financial allocation. In 2015-16, around $45 \%$ of total government spending on health was allocated to PHC services [40]. Though National Health Policy (NHP) 2017 has proposed to increase government funding for PHC and health services, the reality is that government funding for health in India has increased only marginally in last two decades. Similarly, the state government spending on health, proposed to be increased to $8 \%$ of state budget has remained at 5\% of state budget since 2001-02 and increased very marginally [41]. There is a need for more and active public attention and prioritization to increase govt funding for health in India and Indian states. The initial allocation to AB-HWCs in union budget while may be sufficient in the beginning; however, with each passing year the recurrent expenditure for each HWC would be needed. This requires a detailed 'primary healthcare investment plan', preceded by, a detailed cost analysis for PHC services in India. In addition, there is a need for capital expenditure for setting up additional GPHCFs to address the shortage of facilities and meeting the health care needs of growing population, especially in urban areas [42].

Third, the service availability through AB-HWCs need to be continuously upgraded and made locally adapted to meet $80 \%$ or more health needs. In most of the HWCs set up till now, one additional package of services [the seventh package of non-communicable diseases (NCDs)] has been included. However, 5 more packages need to be added and assured. In efforts to achieve the number-based targets for AB-HWCs, for every financial year, focus should not be lost from already established HWCs. The provision of services through these facilities, the utilization by public, assured availability of providers and functioning as per guidelines need to be ensured through continuous oversight, monitoring and innovations. Another approach could be that all the eligible GPHCFs in single geographical area, a block or tehsil, need to be made functional simultaneously to increase utilization and change the perception about government facilities.

Fourth, focus on demand generation for health services through mechanisms such as community participation and social accountability. Getting the facilities functional or strengthening supply side through HWCs (or other similar state specific initiatives) is important; however, it is unlikely to generate utilization; specifically when the previous encounter of people with these facilities has not been pleasant. Simply an upgrade of government health facility might not be enough. People need to come to the health system and experience the change, which will contribute to further demand genration. The supply side strengthening through PHC needs to be augmented by demand generation. This can be achieved with increased and active community involvement; accountability and involving local body representatives and civil society organizations in the process, from the very early stage. In backdrop of recent policy dialogues and approaches adopted for Swachh Bharat Mission (clean Indian mission) and the approach to behavioral economics of nudge need to be examined for suitable adoption in health sector [43-45].

Fifth, the entire process should be guided by use of evidence to scale up interventions and services. A recently published study reported a few common characteristics of better functioning government facilities in India, which included (a) an assured package health services with 'limited intention to availability gap'; (b) Appropriate mix \& sufficient availability of providers; (c) continuum of care with functional referral linkages; (d) initiatives to achieve quality standard; \& (e) community engagement [46]. There is similar evidence from countries such as Brazil; Ghana and South Africa [47-49]. Mohalla Clinics of Delhi and Basthi Dawakhana of Telangana, are empirical evidence that people start attending the government facilities if the facilities are made functional and the services are available in an assured manner, people prefer PHC over complicated and overpowering large hospitals. These initiatives have become popular amongst people and brought poor, marginalized, women and children to government health care system [50-52].

Sixth, 'continuum of care' through coordination between two arms of ABP will contribute to effective utilization. Establishing a functioning referral linkage between HWCs/ PHCs and from secondary and tertiary care services including AB-PMJAY should be focus for policy design and implementation. A good coordination between AB-PMJAY and ABHWCs is not only imperative for streamlining access to care but will be pivotal in providing timely and quality care to the target beneficiaries. A few indicative approaches for 'continuity of care' could be: one, common process for registration of patients at AB-HWCs as well as for AB-PMJAY, through common health identifier with community linkage and registration; two, awareness generation for beneficiaries at 
grassroot level. Three, the training curriculum of Accredited Social Health Activist (ASHA) and other field workers should include a module on AB-HWCs and services and provisions under AB-PMJAY. For a forward referral, AB-HWC can become source of information for AB-PMJAY beneficiaries; fourth, develop effective and two-way referral and inclusion of some outpatient components in AB-PMJAY benefit package and fifth, AB-PMJAY and AB-HWCs to analyse disease and population health risks and trends. The service delivery approach should be beyond referral and the PHC systems need to facilitate the care seeking by proactively seeking appointments for patient going to next level of facilities. Once the treatment plan is prepared at next level of facility, the referral back to PHC level should also be ensured for continuity of treatment and required follow up. This could prove extremely essential and important in context of NCD (including diabetes, hypertension) services.

Seventh, AB-HWCs also need to have dedicated focus on population-based and public health services. It is not a PHC service, if focus is on curative services at facility level only. A well-functioning PHC system needs to cater to those who are not attending the health facilities. People in communities with undiagnosed health conditions need to be identified and brought to treatment, is also part of PHC services. Establishing All India Public Health management Cadre could be one complementary step [3,53].

A few more suggestions on how to make AB-HWCs more effective and better functional are provided in articles published earlier [1, 30, 45, 46].

\section{Discussion}

AB-HWC could, arguably, be termed as the second wave of PHC reforms in India after NRHM in 2005. There is a higher likelihood of success of this initiative than all the earlier initiative, due to many factors. The most important being that AB-HWCs start on an advantage of already strengthened and existing PHC system through NHM between 2005 and 2018. The other factors being the ongoing attention on advancing UHC; states showing increasing and more than ever interest in improving PHC services through their own mechanism and increasing civil society participation and engagement in health [45].

The AB-HWCs could be considered a national initiative to harmonize PHC service delivery on a common platform for all states. This is a major approach in federal system, where health is a state subject as per constitution of India. In the recent years, a number of Indian states have started initiatives to strengthen PHC services, which should provide learnings for AB-HWC and potential harmonization between state initiatives and HWCs (Box 3) [50-52, 54-58]. Clearly, for success, the Indian states have to take leadership in designing
Box 3 PHC strengthening initiatives by Indian states since 2015 [50-52, 54-58]

- Mohalla Clinics, Delhi [50-52, 54]: India's first large scale state government led community clinics initiative in urban settings was launched in July 2015 in Delhi. These clinics, one each for every 10,000 population, are two to three room facilities with provision of primary care services including consultation by doctor with provision of nurse or pharmacist and an attendant. In addition to out-patient consultation services, there is provision of nearly 212 diagnostics tests and 108 medicines available free of cost at these clinics. Soon after launch, these clinics had become immensely popular amongst target beneficiaries and political leadership. As on March 2020, there were 480 clinics functioning with plan to set up 1,000 such clinics.

- Basthi Dawakhana in Telangana [51]: Basthi Dawakhana are arguably India's first urban local body led community clinics. These have been openly claimed to be replication of Mohalla Clinics of Delhi and started by the Greater Hyderabad Municipal Corporation (GHMC). First few Basthi Dawakhana were launched on 6 April 2018. By end of November 2019, there were 115 such clinics with plan to open additional 132 in Telangana state. These clinics have been set up in close collaboration with state Govt of Telangana, Greater Hyderabad Municipal Corporation (the Urban local bodies); Mission for Poverty Elimination in Municipal Areas (MEPMA) and the union government led National Urban Health Mission. There is an improvisation on Mohalla Clinics of Delhi by provision of more services such as public health, preventive and promotive, more integrated referral system and provision of specialist services.

- Family Health Centres, Kerala, India [55]: Government of Kerala in mid-2017 started to upgrade and transform all primary health centres in states as part of Mission Aardram program and renamed these facilities as Family Health Centres (FHC). These facilities focus on upgrading the infrastructure, and provision of more doctors and staff, in closer collaboration with rural elected governments (Panchayati raj Institution) members. There is attention of preventive and promotive health services and by mid of 2018, of nearly 700 PHC in state, nearly 170 were upgraded to Family Health Centres (FHCs). The initial response to initiative has been very positive and utilization to most facilities has nearly doubled with wider community-based services and participation elected representatives and community members. Such facilities are also being considered as future of rural PHC in India.

- Community Clinics in other Indian states [50-52, 56-58]: Inspired by Mohalla Clinics of Delhi, at least a dozen Indian states or Municipal Corporations have either set up or announced similar facilities in their settings. First such clinics were started in Pune by the Municipal Corporation in August 2016. Since then Appla Clinics in Mumbai, Maharashtra (June 2019) and Atal Clinics in Jharkhand (August 2019) have been started, though, the numbers of most such new clinics is in range of 10-50 with promise for more similar facilities. States such as Punjab, Karnataka and Chhattisgarh governments have also planned to start similar clinics. Most recent addition to this list are the 'Sanjivani Clinics' of Madhya Pradesh, \& Janata Clinics of Rajasthan, both launched in December 2019. In early February 2020, Govt of Andhra Pradesh had announced 'Village Clinics' for every 2,000 population in rural parts of state, which appear another promising approach to deliver PHC services in rural areas. However, success of each of these will be dependent upon how well these are implemented.

their own additional initiatives. Even when implementing AB-HWCs, innovative context specific approaches and adaptations for local setting would be needed. 
As part of accountability and governance, the union government initiative such as ranking of states on health, and the proposed ranking of district hospitals should be further expanded to rank the states/districts on their performance on PHC $[59,60]$. As a next step, responsibility for such ranking can be assigned to an independent $\&$ non-governmental organization. The annual report on state of primary health care in India can be started, on the line of Annual Status of Education Reports (ASER) in India [61]. These could be built upon NITI Aayog's state health index and proposed district hospital ranking $[59,60]$.

As India plans to strengthen $\mathrm{cPHC}$, the learnings and initiatives from NRHM/NHM can facilitate the strengthening of AB-HWCs (and the harmonized and integrated NHM and ABP convergence) can help India to make rapid progress towards UHC as analyzed in Table 2. The ongoing attention on health by various approaches should be optimally used to place health higher on development agenda. These opportunities includes the reforms in medical education through the NMC Act, 2019 [34]; dialogue and discourse on the Right to Health [62] which has become stronger following three Indian states considering enactment of a legislation; the recommendation from health subcommittee of 15th Finance commission $[62,63]$ and the renewed global focus on UHC and PHC, as reflected in Astana 2018 and United Nations High Level Meeting (UNHLM) on UHC in Sept 2019 [17, $18]$.

This brings in an important question of when can ABHWC be considered a success in India? To answer this question, the performance of PHC system in India needs to be measured based upon health system outcomes. There would be a need of explicit attention, engagement and linkage to deliver interventions to tackle Social Determinants of Health (SDH) through PHC system. World over, including in India, while inputs to health systems are measured regualrly, the goals on improved health (outcomes and equity), responsiveness, efficiency, and financial protection are not monitored sufficiently. It is expected that this challenge would partially be resolved through initiative of the global UHC monitoring reports. The progress and success of AB-HWCs should also need to be measured against some of the objectives of health systems and functions (Fig. 4). ABHWCs will be credited with the real and lasting fixing of the primary health care system in India, if people start using services at the upgraded facilities, for broad range of health needs. A few more approaches and ideas for effective rollout of AB-HWCs are provided in Appendix 2 [34, 35, 62, 64-68].

In early 2020, novel Corona virus (SARS-CoV2) disease or COVID-19 pandemic hit the world [69]. Across the countries, hundreds of thousand people got affected and many thousands died due to the disease [70]. Experience from countries, affected at the start of pandemic indicated that the asymptomatic patients visiting hospitals for non-COVID-19 health reasons partly contributed in spread of infections to many other people- attending the same facility- for some other health condition. Learning from these experiences, in India, from the start of cases being reported, except for the large
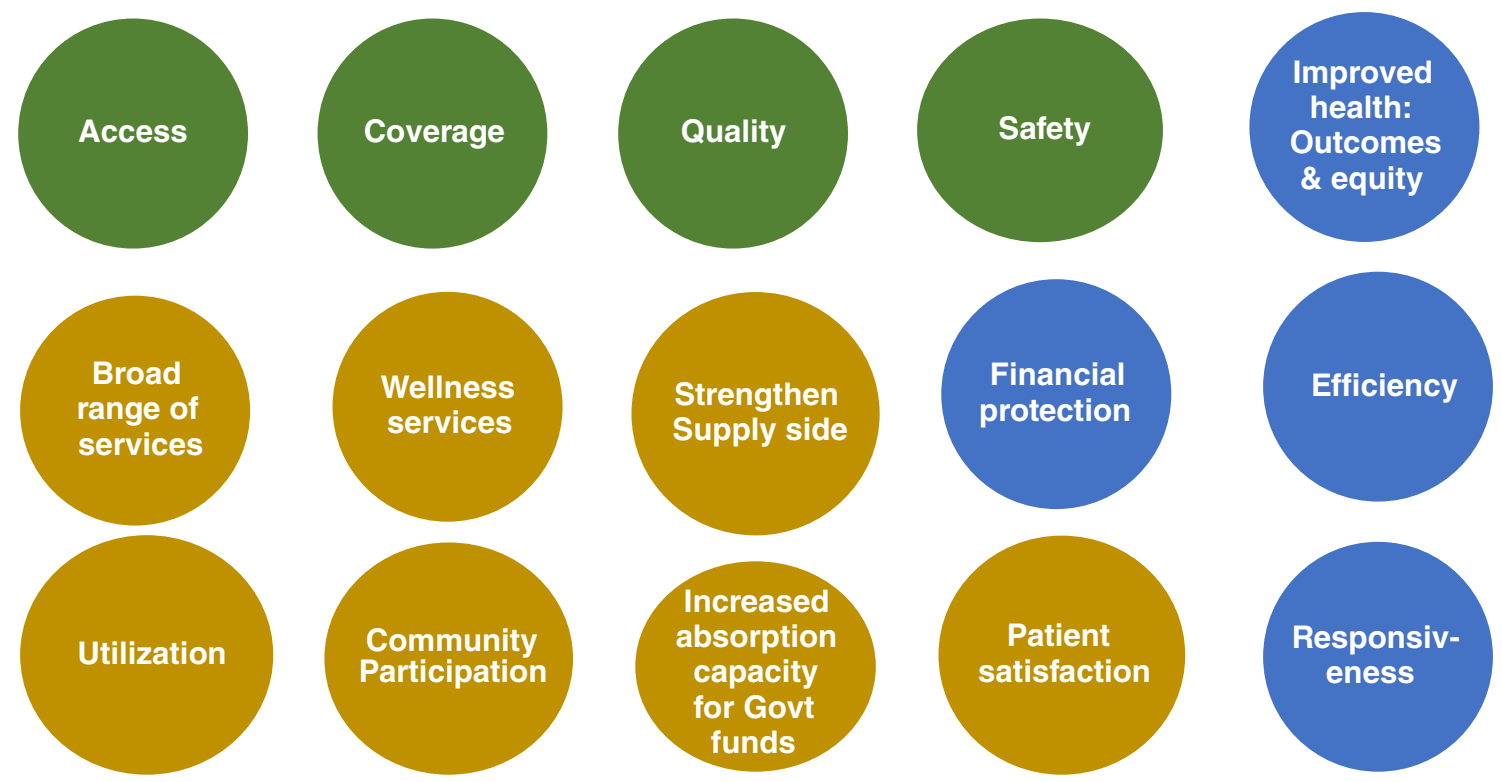

$A B-H W C s$ Ayushman Bharat- Health \& Wellness Centres

Fig. 4 AB-HWCs and potential to impact various components of health systems 
hospitals, most of the private facilities were either partially functioning or out patient departments were completely closed, at least for short period of time. There were reports of gross shortage of even essential health services for nonCOVID-19 patients, which were mostly provided through government primary health care facilities and smaller clinics. COVID-19 pandemic has underscored the relevance of stronger primary health care and is a proof that the world needs better health systems than it has. The weak health systems and primary health care facilities are in those countries, where the burden of diseases are already high and the epidemics and pandemic can further devastate those settings, as had been experienced during the Ebola epidemic in three African countries around 2014 [71, 72].

In late March 2020, COVID-19 pandemic resulted in the government of India to release the guidelines to legalize prescription through telephonic consultation [73]. The home delivery of medicines were allowed during COVID-19 pandemic [74]. These initiatives may be continued through AB-HWCs and have potential to change the PHC service delivery in the years ahead. COVID-19 has indicated that ensuring healthier population in the time ahead would need approaches such as mass education on hand washing, cough etiquettes, personal hygiene and physical distancing. The mental health issues are a major health challenge in India. However, there are not enough mental health services in the country [75]. COVID-19 is expected to exacerbate the psychosocial and mental health issues and the provision of such services should be prioritized through AB-HWCs. COVID-19 challenge should be used as an opportunity to deliver broader public health messages and services and $\mathrm{PHC}$ system is expected to be the most appropriate as well as the cost-effective approach. Alongside, while designing health services, the specific focus needs to be retained on how to make primary health care, in specific, and the health systems, in general, ready and resilient for epidemics, pandemics and natural calamities, which keep affecting, one or other part of the country (and the world), on regular intervals.

\section{Conclusions}

There is a global consensus that universal health coverage can only be achieved on the foundation of stronger primary health care system. There is a renewed attention on strengthening and delivering comprehensive primary health care services in India through health and wellness centres. While the ABHWCs aims to address the existing challenges in PHC system, the effectiveness and success will be dependent upon a rapid transition from policy to implementation stage; focus on both supply and demand side interventions, engagement of community and civil society and other stakeholders, focus on effective and functional referral linkages; ongoing learnings, innovations and mid-course corrections, effective linkage and coordination between two components of Ayushman Bharat program, additional \& complementary initiatives by Indian states, sustained political will \& monitoring and evaluation of the process, amongst other. COVID-19 pandemic has further underscored the need for strengthening the primary health care at the earliest. The experience from India can have lessons and learnings for other low and middle-income countries to strengthen primary health care in journey towards universal health coverage.

Disclaimer The author is the staff member of World Health Organization (WHO). The views expressed in this article are of the author and does not reflects the views and opinion of the organizations he has been associated/ affiliated in the past or at present.

\section{Compliance with Ethical Standards}

Conflict of Interest None.

\section{Appendix 1}

\section{Why AB-HWCs hold the promise to strengthen and deliver comprehensive PHC? [1, 3, 27,29, 31,37]}

System strengthening for better health by tackling identified challenges. The components of HWCs are arguably well thought through and designed keeping in the mind the existing and identified challenges in GPHCF in India [1, 3, 27, 28, 31]. The new provision of services are better informed by emerging evidence as well as changing epidemiological reality.

\section{Approaches to deliver new types of preventive and promotive} health needs. The design of HWCs seems to be cognizant that to tackle triple burden of $\mathrm{MCH}$, ongoing burden of infectious diseases and emerging burden of NCDs, a comprehensive approach is required [29]. This also means a system design for provision of new type of preventive and promotive health services. The preventive and promotive services of earlier period (Family planning, immunization and for disease control) need to be continued. However, new preventive and promotive health services to tackle emerging burden of non-communicable diseases (NCDs): healthy diet, no smoking, physical activity and moderate use of alcohol, require regular participation of individual from the beginning, need to be accelerated and continued to be followed for long.

Shifting service delivery from 'doctor centric' to 'team based' with focus on mid-level healthcare providers (MLHP). The MLHP and other group of such providers known as Community health officers (CHOs) are being deputed to the AB-HWCs. The CHO/MLHP approach has been made institutional and has been given legal status by their inclusion in National Medical Commission (NMC) Act, 2019 with limited 
prescription rights $[31,34]$. This process has witnessed a number of innovations and state public universities (Tamil Nadu, Maharashtra, West Bengal, Gujarat and Jammu \& Kashmir) also offering the certificate programme. These modules, have now been included in B. Sc and Post Basic Nursing Curriculum - which will enable course to be offered in 2,500 Nursing Colleges with annual admission capacity of 112,546 candidates [35].

I of 'Illness' proposed to be replaced with We to make it 'Wellness' care system. This has been proposed through change in the approach to service delivery from routine curative care to more of community engagement and other cadre of providers. The traditional health systems are also being mainstreamed in health services and includes, regular Yoga sessions and Health promotion activities at AB-HWCs; Awareness on 'Eat Right India' and promotion of 'Fit India initiatives' [36, 37]; provision of Food adulteration detection kits at PHCs; Nutritional counseling at AB-HWCs using the provisions of POSHAN Abhiyan under Ministry of Women \& Child Development; Preventive and Promotive Healthcare Services involving Behavior change communication through Self Help Groups, youth and other organized groups, School Health Ambassadors, Village Health Sanitation and Nutrition Committees (VHSNCs), Panchayati raj Institutions (PRIs) and urban local bodies (ULBs), etc. All these are further expected to bring focus on wellness in health services. This is also aligned to seven components of Swasth Nagrik Abhiyan as proposed in NHP 2017.

\section{Appendix 2}

\section{Proposed additional measures to ensure success of AB-HWCs and to strengthen CPHC in India [34, 35, 60- $66,74]$}

Shift health planning unit from districts to sub-district levels. Considering 'Health' is a state subject in India, it is appropriate that the discourse on health with financial protection and allocation by states for health services becomes part of state level policy dialogue. Health planning units in India are at district level as is the case in most other countries as well. However, in most countries, the districts are at population of 50,000 to 300,000 . Considering that an average district in India is around 20 Lakh ( 2 million) population, even district level planning may not be detailed enough and to ensure planning for every 200,000 to 300,000 ; the 'sub-district level health planning' should be considered in India. A beginning can be made by selected Indian states and with time, there would be need for 8,000 planning units, one for each block, rather than nearly 760 at district level at present. This could help in equitable planning and allocation of funds, HR and infrastructure.

Innovative approaches for setting up HWCs. The states have used the opportunity to set up HWCs to develop appropriate and innovative approaches at various levels which includes, Partnerships with non-governmental organizations (NGOs) for Urban-PHCs in Karnataka; Public-Private Partnerships through E-urban PHCs in Andhra Pradesh \& Telangana; as well as Medical Officer led models in Kerala, Tamil Nadu \& Puducherry. On the similar line, the Community Health Officers (CHOs) are being selected amongst various approaches such as B.Sc Community Health equivalent in Assam and Chhattisgarh; Ayurveda Practitioners in Maharashtra and Nurses in states such as Jharkhand, Madhya Pradesh, Uttar Pradesh, Andhra Pradesh, Punjab, Karnataka, Telangana, West Bengal, Andaman \& Nicobar Island, Dadar \& Nagar Haveli and all North Eastern states except Assam. The selection of CHO is based upon a mix of health staff in Bihar, Odisha, Gujarat, Rajasthan, Jammu \& Kashmir (J\&K) Uttarakhand, Haryana, Daman and Diu, and Unani Practitioners as well in J\&K and Maharashtra. The enactment of the National Medical Commission (NMC) Act, 2019 is become a supporting legal instrument for empowering community. The NMC act of 2019, which proposes to empower non-physician providers to prescribe a limited range of medicines. In wake of COVID-19 pandemic, the Board of Governors for Medical Council of India had released new tele-consultation guidelines, which opens a new opportunity for making health services accessible in under-served and difficult areas, in the time ahead. These, along with other opportunities should be used to redesign PHC system as team based and people centric. However, success and effective implementation of this initiative need a stronger focused monitoring of the process.

Revival and expansion of community and civil society participation in health. The engagement with communities, elected representatives, civil society organizations and interest groups in designing the system which people need, demanding for better health services and working together for common cause is increasingly being recognized. This is resulting in opening and supporting many new avenues which directly or indirectly may contribute to better health outcomes and systems in India. These include national knowledge platform; Innovation and learning centres; Ayushman Bharat Ambassadors \& messengers in school; renewed focus on community clinics or frontline health service; health getting far more attention in media as well as Political agenda in general election. There are Sustained expert engagement, research and evidence and Strengthened $\mathrm{CSO} / \mathrm{CBO}$ 
engagement for health; Development/revision of many operational guidelines, broadly supplemented by global dialogues and commitments for PHC strengthening.

Appropriate use of digital and mobile health solutions. Making PHC functional needs measuring the results of interventions and improving accountability. Digital technologies can be leveraged to address health challenges in remote areas, generate awareness about health entitlement, deliver preventive and promotive health services, empower people and support communities to look after their own health. Information and communication technology can be used for ensuring referral linkage; measuring results to enhance accountability is making information on health care entitlements and performance publicly available in a transparent manner. The planning and early role out needs to be supported by a robust IT enabled monitoring and evaluation process; real time dash boards, amongst others would be needed to ensure that program designs are implemented, facilities so created are being utilized, services scaled up, the bottlenecks are regularly being identified and corrective measures being taken to improve performance.

\section{Strengthen implementation and operational research capac-}

ity. There are a few policy questions which need to be answered in due course. ABP should also be an opportunity to strengthen operational research to support scale up based upon evidence and understanding. There would be a very important role of technical support and implementation research for identifying operational questions and then seeking answers in a scientific way through operational and implementation research. Dept. of Health Research (DHR) and National Knowledge Platform (NKP) as proposed under NHM can play an important role in the process. The emerging policy questions with possible need for operational research need to be a focus. There is a role of evidence, implementation research and capacity building in the process. The institutional mechanisms at both national and sub-national level, with sufficient government funding to support implementation research would be needed. Such platforms should bring policy makers, academic researchers and program managers and all other stakeholders together.

Renewed inter-sectoral collaboration between health and education. One of the example of how HWC dialogue has broadened the scope of health beyond curative care and beyond health department is the concept of Ayushman ambassadors \& Messengers. As part of HWCs initiative, a coordination has been established with department of education. Two teachers, preferably one male and one female, in every school were proposed to be designated "Health and Wellness or Ayushman Ambassadors". Prior to that the teachers are to be trained in health promotion and disease prevention for one hour every week, through a pre-decided curriculum. The school children are selected as health and wellness or Ayushman messengers and key health messages such as vaccination and hand-washing are communicated to the families through school children. This idea and concept was further formalized with the formulation of guidelines for school health under HWCs, released in Feb 2020.

\section{References}

1. Lahariya C. 'Ayushman Bharat' program and universal health coverage in India. Indian Pediatr. 2018;55:495-506.

2. MoSPI. Key indicators of social consumption in India: Health. NSS 71st round. January - June 2014. New Delhi: Government of India, Ministry of Statistics and Programme Implementation; 2015.

3. Government of India. National Health Policy 2017. New Delhi: Ministry of Health and Family Welfare, Government of India; 2017.

4. Govt. of India. Guidelines for Health and Wellness Centres in India. Nirman Bhawan, New Delhi: Ministry of Health and Family Welfare, Govt of India; 2019.

5. Government of India. Health Survey and Development Committee, 1946.

6. Govt of India. Community Development Program, 1952.

7. Govt of India. India's Journey Towards Universal Health Coverage. New Delhi; Special report released on 22 September 2019.

8. Ministry of Health and Family Welfare. Rural health statistics 2018. Nirman Bhawan, New Delhi: MoHFW; 2019.

9. World Health Organization. Adoption of constitution of WHO. Geneva: WHO; 1948.

10. Govt of United Kingdom. National Health Services. Great Britain, 1948.

11. Lahariya C, Khanna R, Nandan D. Primary health care and child survival in India. Indian J Pediatr. 2010;77:283-90.

12. WHO. World Health Organization. Available at: https://www. searo.who.int/entity/world_health_day/previous/en/. Accessed 24 Mar 2019.

13. World Health Organization. World Health Day 2019. Available at: https://www.who.int/campaigns/world-health-day/world-healthday-2019. Accessed 24 Mar 2019.

14. Declaration of Alma-Ata. International Conference on Primary Health Care, Alma-Ata, USSR, 6-12 September 1978. Available at: https://www.who.int/publications/almaata_declaration_en.pdf? ua $=1$. Accessed 7 Jan 2019.

15. World Health Organization. World Health Assembly (WHA) Resolution of 2005. Available at: https://apps.who.int/ medicinedocs/documents/s21475en/s21475en.pdf. Accessed 24 Mar 2019.

16. UNGA resolution of 2012. Health: Essential for sustainable development. United Nations Resolution on Universal Health Coverage. Available at: https://www.who.int/universal_health_coverage/un resolution/en/. Accessed 24 Mar 2019.

17. Declaration of Astana. Global Conference on Primary Health Care. Astana, Kazakhstan, 25-26 October 2018. Available at: https:// www.who.int/docs/default-source/primary-health/declaration/ gcphc-declaration.pdf. Accessed 24 March 2019.

18. United National High-level Meeting on Universal Health Coverage. Available at: https://www.uhc2030.org/un-hlm-2019/. Accessed 24 Mar 2019

19. World Health Organization. Primary Healthcare Fact Sheet. Available at: https://www.who.int/docs/default-source/ documents/campaign-essentials-whd19.pdf?sfvrsn=bda1 1 fof 2 . Accessed 24 Mar 2019. 
20. Ministry of Health \& Family Welfare. The task force on primary healthcare in India. Nirman Bhawan, New Delhi: MoHFW; 2015.

21. Govt of India. National Health Policy of India. New Delhi: MoHFW; 1983.

22. Lahariya C, Khandekar J, Prasuna JG. Meenakshi. A critical review of national rural health mission in India. Int J Health. 2007;6. Available at: https://ispub.com/IJH/6/1/6287. Accessed 18 Dec 2019.

23. Govt of India National Health Policy 2002. New Delhi: MoHFW, Govt of India; 2002.

24. Govt of India. National Urban Health Mission. New Delhi: MoHFW, Govt of India; 2013.

25. Govt of India. NRHM Framework for Implementation. New Delhi: MoHFW, Govt of India; 2012.

26. Govt of India. India's Progress Towards MDGs: Final Country Report. Available at: https://www.mospi.gov.in/sites/default/files/ publication_reports/MDG_Final_Country_report_of_India_ 27nov17.pdf. Accessed 24 Mar 2019.

27. Planning Commission. Report of high level expert group on universal health coverage in India. New Delhi: Planning Commission; 2012.

28. Govt of India. $12^{\text {th }}$ Five Year Plan of India. New Delhi: Planning Commission; 2012.

29. PHFI, ICMR. India. Health of nations state. Report of first state level burden of diseases in India. New Delhi: ICMR

30. Lahariya C. 'More, better, faster \& sustained': Strengthen primary health care to advance universal health coverage. Indian J Med Res. 2019;149:433-6.

31. Govt of India. Health and Wellness Centres. MoHFW Govt of India. Available at: https://ab-hwc.nhp.gov.in/. Accessed 24 Mar 2019.

32. National Health Authority. Annual Report of Pradhan Mantri Jan Aarogya Yojana. Nirman Bhawan, New Delhi: NHA, MoHFW; 2019.

33. Kurian OC, Chikermane G. Can PMJAY fix India's healthcare system: Crossing five hurdles on path to universal health coverage. Observer research foundation (ORF) occasional paper 172, New Delhi; 2018. Available at: https://www.orfonline.org/research/ can-pmjay-fix-india-healthcare-system-crossing-five-hurdles-pathuniversal-health-coverage-44940/. Accessed 18 Dec 2019.

34. Govt of India. The National Medical Commission Act, 2019.

35. Govt of India. Presentation made by Govt program manager on health and wellness centres in a meeting on July 2019. New Delhi: Ministry of Health and Family Welfare. 2019.

36. Eat Right India. Available at: https://eatrightindia.gov.in/index. Accessed 22 Mar 2020.

37. Fit India. Available at: http://fitindia.gov.in/. Accessed 22 Mar 2020.

38. Save the Children. Primary Health Care First. Available at: https:// resourcecentre.savethechildren.net/sites/default/files/documents/ primaryhealth_care_first_executive_summary.pdf. Accessed 24 Mar 2019.

39. Doherty G, Govender R. 'The Cost Effectiveness of Primary Care Services in Developing Countries: A Review of International Literature', Working Paper No. 37, Disease Control Priorities Project, World Bank, WHO and Fogarty International Centre of the US National Institutes of Health; 2004.

40. Govt of India. National Health Accounts 2015-16. Ministry of Health and Family Welfare, Government of India, Oct 2018.

41. Ahuja R. Government health spending in India: Who will fund the target of 2.5 per cent of GDP? J Dev Policy Prac. 2019;4:3-11.

42. Lahariya C. Strengthening primary healthcare: From promises to reality. Ideas For India. Available at: https:/www.ideasforindia.in/ topics/human-development/strengthening-primary-healthcarefrom-promises-to-reality.html. Accessed 18 Dec 2019.
43. Govt of India. Swachch Bharat Mission. Available at: https:// swachhbharatmission.gov.in/sbmcms/index.htm. Accessed 18 Dec 2019.

44. Ministry of Finance. Economic Survey of Govt of India 2019-20. Ministry of Finance. 2019. Released on 4 July 2019.

45. Lahariya C, Roy B, Shukla A, et al. Community action for health in India: Evolution, lessons learnt and ways forward to achieve universal health coverage. WHO South-East Asia J Public Health. 2020;9:82-91.

46. Lahariya $\mathrm{C}$, Sundararaman $\mathrm{T}$, Ved RR, et al. What makes primary healthcare facilities functional, and increases the utilization? Learnings from 12 case studies. J Family Med Prim Care. 2020;9: 539-46.

47. Center for Global Development. Millions Saved. Brazil's Programa Saúde da Família. Available at: http://millionssaved.cgdev.org/ case-studies/brazilsprograma-saude-da-familia. Accessed 24 Mar 2019.

48. Assegaai T, Reagon G, Schneider H. Evaluating the effect of wardbased outreach teams on primary healthcare performance in north West Province, South Africa: A plausibility design using routine data. S Afr Med J. 2018;108:329-35.

49. Assan A, Takian A, Aikins M, Akbarisari A. Challenges to achieving universal health coverage through community-based health planning and services delivery approach: A qualitative study in Ghana. BMJ Open. 2019;9:e024845.

50. Lahariya C. Mohalla clinics of Delhi, India: Could these become platform to strengthen primary healthcare? J Family Med Prim Care. 2017;6:1-10.

51. Lahariya C. Basthi Dawakhana of Telangana, India: The first ULB led community clinic initiatives of India. J Family Med Prim Care. 2019;8:1401-7.

52. Lahariya C. A replicable model for urban healthcare. India Development Review. Available at: https://idronline.org/areplicable-model-for-urban-healthcare/. Accessed 22 Mar 2020.

53. NITI Aayog. Five-year strategic plan (2018-22) for new India at 2022. NITI Aayog, Govt of India.

54. Lahariya C. Abolishing user free and private wards in public hospitals. Econ Polit Wkly. 2016;41:30-1.

55. Govt of Kerala. Family Health Centres. Can Kerala's Bold Experiment to Overhaul Public Health from Bottom up Succeed? Available at: https://scroll.in/pulse/852553/can-keralas-boldexperiment-to-overhaul-public-health-from-bottom-up-succeed. Accessed 18 Dec 2019.

56. Govt of Maharashtra. Aapla Clinics. Available at: https:// indianexpress.com/article/cities/mumbai/like-delhi-maharashtrato-get-mohalla-clinics-for-primary-healthcare-5603945/. Accessed 22 Mar 2020

57. Govt of Rajasthan. Janata Clinics of Rajasthan. Available at: https://government.economictimes.indiatimes.com/news/ healthcare/rajasthan-healthcare-to-go-digital-with-janta-clinicslaunch-in-jaipur/71670391. Accessed 14 Jan 2020.

58. Govt of MP. Sanjivani Clinics. Available at: https://www. freepressjournal.in/indore/inspired-by-delhis-mohalla-clinics-mpgovt-to-inaugurate-first-sanjeevani-clinic. Accessed 18 Dec 2019.

59. Govt of India. NITI State Health Index. June 2019. Available at: http://social.niti.gov.in/uploads/sample/health_index_report.pdf. Accessed 18 Dec 2019.

60. Govt of India. District Hospital Ranking to be Released in India. Available at: https://niti.gov.in/writereaddata/files/document publication/District\%20Hospital\%20Booklet final.pdf. Accessed 22 Mar 2020.

61. Pratham. Annual Survey of Education Report. Available at: http:/ www.asercentre.org/p/158.html. Accessed 22 Mar 2020.

62. Right to Health in India. Available at: https://www.indiaspend.com/ in-rajasthan-indias-first-right-to-healthcare-law-takes-shape/. Accessed 22 March 2020. 
63. Govt of India. $15^{\text {th }}$ Finance Commission of India. Available at: https://fincomindia.nic.in/. Accessed 22 Mar 2020.

64. World Health Organization. WHO world health report 2013: Research for universal health coverage. Geneva: WHO; 2013.

65. Rifkin SB. Examining the links between community participation and health outcomes: A review of the literature. Health Policy Plan. 2014;29:ii98-106.

66. Gaitonde R, San M, Muraleedharan VR, Hurtig A. Community action for health in India's national rural health mission: One policy, many paths. Soc Sci Med. 2017;188:82-90.

67. World Health Organization. Global Action Plan for Health \& Wellbeing. WHO and Other Agencies. Sept 2019.

68. Sharma NC. Govt launches school health Programme under Ayushman Bharat. New Delhi; Live Minit: 12 Feb 2020. Available at: https://www.livemint.com/news/india/govtlaunches-school-health-programme-under-ayushman-bharat11581517583719.html. Accessed 22 Mar 2020.

69. Lodha R, Kabra SK. COVID-19: How to prepare for the pandemic? Indian J Pediatr. 2020;87:405-8. https://doi.org/10.1007/s12098020-03293-0.

70. World Health Organization. Coronavirus Disease (COVID-2019) Situation Reports. Available at: https://www.who.int/emergencies/ diseases/novel-coronavirus-2019/situation-reports. Accessed 10 May 2020.

71. World Bank. Ebola: Most African Countries Avoid Major Economic Loss but Impact on Guinea, Liberia, Sierra Leone
Remains Crippling. World Bank (2016). Available at: http:// www.worldbank.org/en/news/press-release/2015/01/20/ebolamost-african-countries-avoid-major-economic-loss-but-impact-onguinea-liberia-sierra-leone-remains-crippling Accessed 21 Dec 2019.

72. Ravi SJ, Snyder MR, Rivers C. Review of international efforts to strengthen the global outbreak response system since the 2014-16 West Africa ebola epidemic. Health Policy Plan. 2019;34:47-54.

73. Govt of India. Telemedicine practice guidelines: Enabling registered medical practitioners to provide healthcare using telemedicine. 25 March 2020. Nirman Bhawan, New Delhi: Ministry of Health and Family Welfare; 2020. Available at: https://www. mohfw.gov.in/pdf/Telemedicine.pdf. Accessed 10 May 2020.

74. Times of India. Centre Permits Doorstep Delivery of Medicines during Covid-19 Lockdown. Available at: https://timesofindia. indiatimes.com/india/centre-permits-doorstep-delivery-ofmedicines-during-covid-19-lockdown/articleshow/74829942.cms. Accessed 10 May 2020.

75. Lahariya C. Strengthen mental health services for universal health coverage in India. J Postgrad Med. 2018;64:7-9.

Publisher's Note Springer Nature remains neutral with regard to jurisdictional claims in published maps and institutional affiliations. 